Pakistan Journal of Humanities and Social Sciences

October - December 2018, Volume 6, No. 4, Pages 443 - 457

\title{
Appraisal of the Determinants of Energy Use in LAPAI Local Government
}

\author{
Musa Abdullahi Sakanko ${ }^{1}$, Joseph David ${ }^{2}$ and Abdullahi Yakubu ${ }^{3}$ \\ ${ }^{1,2,3}$ Department of Economics, Ibrahim Badamasi Babangida university Lapai, Niger State \\ Email: Sakanko2015@yahoo.com
}

\begin{abstract}
The paper investigates the determinants of energy use in Lapai Local government area of Niger state, Nigeria using a cross-sectional data randomly collected from 117 respondents in the Lapai. Employing the descriptive statistics and Multinomial Logistics regression model to capture the characteristics of the respondents and the determining factors of energy use in Lapai respective. The empirical result obtained revealed that people use more of the traditional energy sources (firewood and charcoal) because of its availability and affordability. Income level, family size, educational status, and occupational status are the major determinants of the use of the modern energy sources relative to traditional energy sources. The study thus recommends The Government through ministry of power and environment should come up with suitable policies that will shift the attention of using biomass energy source to modern energy source, Government and environmental agencies should introduce safe and sufficient energy source in other to reduce burden on the use of biomass in the country so as to reduce the level of pollution and erosion. The actions of the local government authorities towards the improvement in the availability and access to modern energy source so a s to reduce the use of traditional energy sources as well as improvement in the income level and access to education of individuals in the local government.
\end{abstract}

Keywords: $\quad$ Energy use, Determinants, Lapai, Multinomial Logit model

\section{Introduction}

No activity is possible without energy and its total amount in the universe is fixed. In other words, it cannot be created or destroyed but can only be changed from one form to another. Energy source can be classified as renewable and non-renewable forms. Renewable energy sources are those which cannot be exhausted. It includes geothermal, solar energy, water, wind energy, and crop residues while the non-renewable forms are mainly those which 
can be exhausted after some years. It includes petroleum products such as kerosene, nuclear, natural gas and coal.

Nigeria as a nation is blessed with abundant mineral deposits which include modern and traditional energy resources which are aimed at providing both households and industries with the type of energy use either traditional (Biomass) or modern (Kerosene, liquefied petroleum, and electricity) energy. More than 20 percent of the energy use in Nigeria is consumed by households in both rural and urban areas (Mekonnes and Kohlin 2008). Household per capita energy use in Nigeria and other sub-Sahara Africa is greater than that of developing nations despite the majority of the portion is often provided by non-commercial fuels that hardly reflect in official statistics. Research have shown that majority of the households in Sub-Sahara Africa which Nigeria is not an exception and other developing nations in Asia and South America depends on biomass fuel to meet their energy needs ( Mekonnes and Kohlin 2008).

The household energy sector is divided into three sub-sectors: biomass fuels (wood, dung, and crop waste), hydrocarbon fuels (gas and kerosene), and electricity. In many communities, people use a combination of biomass fuels and hydrocarbon fuels in order to save electrical cost (IEA, 2006). The adverse effect of biomass fuel have not over the years been noticed by the larger population and even for those that have noticed the effects could not easily switch from the use of biomass energy to modern energy due to the cheapness, availability and affordability of the biomass in their locality. Per capita income of Nigerian households most especially people living in rural communities is extremely lower than that of the households in urban areas, leaving the rural areas with no other choice than to adhere to the continuous use of biomass energy because of its affordability and easy accessibility. The high dependence in the biomass fuel use of the majority of Nigerian population has left the country with negative environmental effects. The Nigerian government had come up with policies which will shift the attention of the use of traditional source to the modern source in other to reduce its environmental effects on the population but the policy has a conflicting objective, because a policy that discourage or tend to ban use of biomass fuel with an upward cooking gas and kerosene price. Therefore, the policy needs to be revisited in order to have balanced objective.

With rapid increase in Nigerian population with the majority of the population living in rural areas than urban cities where biomass fuel is consumed more. This has indirectly caused environmental hazards such as pollution, deforestation, openness of soil to erosion, 
soil and land degradation etc. (Bello, 2010) believed that reason why there is continuous use of biomass is because it serves as source of income for people in rural and some urban cities. Also, Mekonnes and Kohlin (2008) argue that while the use of woody biomass as fuel and as construction materials contribute to deforestation and forest degradation, other biomass types such as animal dungs as fuel implies that it might not be available for use as fertilizer thus, leading to land degradation and consequently reduction in agricultural output.

According to the energy ladder hypothesis or theory is one of the commonest hypothesis concepts of energy use among household. The theory state that household with lower income tends to use traditional means of energy source such as charcoal, firewood and so on while household with high income make use of modern means of energy source such as gas, solar, electricity etc Baldwin, 1986: Smith 1987, Leach 1992). Furthermore, it has also showed that household with lower income and higher income uses biomass such as wood, kerosene, charcoal and gas, electricity respectively (Heltberg et al 2005). The theory postulates that household use of energy is related to that of consumer behavior.

Furthermore, it also state that when household income increases, the consumption of energy by household didn't only increase rather, household shift from traditional means of energy source to modern means of energy source and it also depends on their psychological attitude.

Since it is obvious that consumer wants are unlimited and consumer has at his/her disposal a purchasing means which is not only scarce but has an alternative uses. This as a result of scarcity of resources the consumer cannot satisfy all his wants. The consumer has to choose as to which is to be satisfied and which his resources permit. Therefore, the consumer is confronted in choice making. Hence, consumers make a choice base on what is available and can afford at a point that will give him/her maximum satisfaction. When you compare the needs and means in terms of available energy the consumers will always goes for biomass fuel.

Based on the above the following research questions were pulled: To what extent do socio-economic variables such as family size, education status and occupation determine energy use in Lapai, Niger State? What kind of energy uses most in Lapai, Niger State? Does increase in household income change its energy use?

The objective of this study is to ascertain the determinants of energy use in Lapai, Niger State, Nigeria over a specific period of time. The study is divided into five sections. 
Section two after the introduction is literature review, section three methodology, section four recommendations and conclusions and section five References.

\section{Literature Review}

Energy in a layman's language is often synonymous with strength or force or better still fuels. In technical terms energy is that thing that can be used to produce work. Yergin (1989) defines energy as anything that makes it possible to accomplish physical work, anything capable of bringing about movement against resistance. Energy is the capacity to perform or carry out work.

Abott (2001) define energy as something that appears in many different forms which are related to each other by the fact that conversion can be made from one form of energy to another. Dave (2004) in his definition define energy as a property or characteristic (or trait or aspect) of matter that makes things happen, or, in the case of stored or potential energy has 'the potential' to make things happen. Energy is defined as a measure of the ability of a body or system to do work or produce a change, expressed usually in joules or kilowatt hours (Gordon, 1996).

Sakanko and Obilikwu (2018), analyzed the determinants of demand for charcoal in Niger State, employing descriptive statistics and Logistic regression model and found that the price of charcoal, and household income had negative impacts on the demand for charcoal; while, availability of charcoal relative to other energy sources, price of alternative energy sources; size of household, and low risk involved in charcoal usage had positive influence on the demand for charcoal in the state.

Adeyemi and Adereleye (2016), examined the determinants of household choice of cooking energy in Ondo state, Nigeria, using descriptive statistics and multinomial logit and found that household income, level of education, household size, occupation of respondents, and nature of dwelling houses and ownership of dwelling houses are the significant factors influencing fuel choice.

Maurice, Umar and Zubairu (2015) examined the factors that influence the consumption of Fuel wood in some selected local government areas of Taraba State, Nigeria. Employing Multi-stage random sampling technique to analyze the cross-sectional data randomly collected from 150 respondents, the results revealed that marital status and cost of alternative fuel (kerosene) positively influenced fuelwood consumption by households, while monthly income, labour and cost of fuelwood per kilogramme negatively influenced fuelwood consumption by households. 
Bamiro and Ogunjobi (2015) accessed the determinants of household energy consumption in Ogun State, Nigeria. Analyzing the data collected randomly with the use of stratified random sampling technique from 150 respondents using Multinomial Logit and Tobit regression models, the result obtained revealed that while the price of wood, price of kerosene, and family size positively determines fuel choice, prices of wood, electricity and kerosene negatively determines household's monthly fuel expenditure.

Madukwe (2014) investigated the domestic energy usage pattern of households in selected urban and rural communities of Enugu State Nigeria. Using data randomly collected from 300 households. ANOVA and regression analysis technique were used to test for association. The study revealed that while households in urban areas rely more on kerosene usage, most households in rural areas rely heavily on the use of firewood. Similarly, economic factors such as the accessibility of an energy source, educational status, the price of an energy source, and income level were found to positively influence the type of energy used.

Bekele, Negatu and Eshete (2016) analyzed the determinants of household energy demand in Ethiopia. Employing estimation technique of Weighted Average Least Square (WALS) to analyze the cross-sectional data collected from 499 households in the study discovered that age and educational status of household head, ownership of electric appliance (meter and refrigerator), family size, monthly energy expenditure and total expenditure are significant determinants of energy use in Ethiopia.

Ogwanike, Ozughala and Abiona (2014), investigated household energy use and determinants: Evidence from Nigeria in 2013 using descriptive statistics and multinomial logit model and found that most household in Nigeria uses firewood as cooking fuel and kerosene for lighting. The study also revealed that Nigerian households do not have adequate access to environmentally friendly modern energy sources.

Onoja and Idoko (2012) examined the influencing factors or determinants of fuelwood demand in rural and semi-urban farm households of Kogi State, sampling 80 households randomly from the agricultural zones of the state. Employing two stage least square technique, the price of fuel wood, price of kerosene, household size and household income level are discovered to be the significant determinants of fuel wood demand in the state.

Adepoju, Oyekale and Aromolaran (2012) studied factors influencing domestic energy choice of rural households in Ogun State, Nigeria, using data collected randomly from 
the sampled households. Employing Logistics regression analysis, the study revealed that while household size and absence of formal education or primary education influences the use of charcoal, marital status, farm ownership, farm size, occupational status and expenditure on charcoal negatively influences the demand for charcoal in rural households of Ogun state, Nigeria.

Njong and Johannes (2011), studied An Analysis of Domestic Cooking Energy Choices in Cameroon, using multinomial logit model and found that the level of education, distance of the household from urban centers, whether or not the household owns the dwelling unit and whether or not the dwelling unit is traditional or modern type are important factors that determine household cooking energy choice. The study also reveals that fuel wood is the principal cooking fuel for the majority of households in Cameroon.

Ouedraoge (2006), analyzed the factors determining urban household energy preference for cooking in Ouagadougan, Burkina Faso from 2000 to 2005 using multinomial logit model and discovered that the inertia of household cooking energy preferences are due to poverty factors such as low income, household poor access to electricity or primary and secondary energy use. Findings further revealed that the managerial effect of household income is not significant for firewood and charcoal. Also, it revealed that the managerial effect of primary education level is significant at one percent level with positive sign.

Shittu et al. (2004) examined the demand for energy among households in Ijebu Division, Ogun State, Nigeria, using linear logit model and found that the influence of education and household size on household energy used were insignificant, while income and age of household heads revealed significant influence.

Mekonnen and Kohlin (2008) studied the determinants of household fuel choice in major cities in Ethiopia from 2004 to 2006, using multinomial logit model and found that as households' total expenditures rise, they increase the number of fuels used, even in urban areas and they also spend more on the fuels they consume. This study shows the relevance of fuels stacking (multiple fuel use) in urban areas in sub-Saharan Africa. While income is an important variable, the results of this study find other variables such as family size, household location and level of education as important determinants of household fuel choice in Ethiopia.

Explicitly there is no any existing accessible literature on the determinants of energy use in Lapai Local Government of Niger State, Nigeria. Most of the previous studies in Nigeria that examined the determinants of energy use are carried out in urban centers (State 
and Federal) see Maurice, Umar and Zubairu, 2015; Bamiro and Ogunjobi, 2015; Madukwe, 2014; Ogwumike, Ozughalu and Abiona, 2014); and Sakanko and Obilikwu (2018). Therefore, need to study the determinants of energy use in a rural area like Lapai to ascertain the influencing factor and to provide police implication for the way forward.

\section{Methodology}

The analytical model of this study is adapted from Ogwumike et al. (2014) and Bamiro and Ogunjobi (2015). The study adapted utility theory of consumer behavior which of the view that consumers are rational human beings with unlimited wants and they make choices based on what is available and affordable that will maximize satisfaction with their little income. The study assumed that people of Lapai local Government make choice on energy use on rationality since they have the choice to choose between the traditional and modern energy. The use of energy in Lapai local government is group into traditional and modern energy sources, that is;

$$
E N E U=f(T, M)
$$

Where ENEU is energy use, while $T$ and $M$ represent Traditional and modern energy sources respectively. Energy sources such as electricity, gas, solar, nuclear are grouped under modern energy sources while energy sources such as firewood, charcoal, animal dung, plant residuals, sawdust etc. are grouped under traditional energy sources while kerosene is grouped in-between the sources, this is due to the smoke the use of kerosene produce which is perceived to be harmful to human health and even makes the cooking utensils dirty. Consequently, the use of solar and nuclear energy is not common in the study area while the use of firewood and charcoal is popular among the population, therefore electricity and gas will make up our modern energy source. Thus the functional relationship is represented as;

$$
\begin{aligned}
& T=f(F, C h, K) \\
& M=f(E, G, K)
\end{aligned}
$$

Where $F$ represent firewood; $C h$ represent charcoal; $K$ represent kerosene; $E$ denotes electricity; and $G$ represent gas. In the literature, apart from factors such as the availability and accessibility (or affordability) of energy sources, income, family size, educational status and occupation of household influences the decision of energy use in households. Thus Eqn. (1) transforms to;

$$
E N E U=f(A V A I L, A C C E S S, Y, F A M Z, E D U, O C C)
$$

Where AVAIL, ACCESS, Y, FAMZ, EDU, OCC denotes the availability of energy, access or affordability of energy, income level, family size, educational level and occupation 
respectively. Based on the objective and scope of this study, the data for the study will be a cross-sectional data which will be collected primarily from the study location, Lapai local government area of Niger state Nigeria. Lapai local government area of Niger state is among the 25 local governments in the state located between latitude $9^{\circ} 03^{\prime} 00^{\prime \prime}$ North of the equator and longitude $6^{\circ} 34^{\prime} 00^{\prime}$ " east of the Greenwich meridian with an estimated population of 110,127 according to 2006 census. A structured questionnaire will be employed for data collection with the use of stratified sampling technique which will give all the population in each wards equal chances of been selected and this will amount to the administration of 150 questionnaires.

To effectively analyze the determinants of energy use in Lapai local government area of Niger state, the Multinomial Logistic Model will be employed which as previously stated was adapted from Ogwumike et al. (2014) and Bamiro and Ogunjobi (2015). The choice of this model is guided by the categorical nature of energy use. The response variable energy use takes the value zero, one and two; zero if firewood or charcoal is used; one if kerosene is used and two if electricity or gas is used. Other variables such as availability and accessibility of energy sources, income, family size, education and occupation takes the value one and zero; 1 if yes and zero if otherwise. The multinomial logistics model is thus specified as;

$$
\operatorname{Pr}(Y i=j)=\frac{e^{\beta j X i}}{\sum_{k=0}^{3} e^{\beta k X i}}
$$

Where $\operatorname{Pr}\left(\mathrm{Y}_{i}=j\right)$ is the probability of using energy $j ; i$ denotes the number of crosssectional observations; $j$ denotes the energy used (firewood and charcoal; kerosene; or electricity and gas); $e$ is an exponential function; $\beta$ represents the vector of parameters to be estimated; $\mathrm{Y}$ and $\mathrm{X}$ denoted the response variable and vector of the explanatory variables respectively.

From the multinomial logistic model in Eqn. (5) we develop our model for empirical analysis from the functional representation in Eqn. (4) as thus;

$\operatorname{Pr}\left(\mathrm{ENEU}_{i}=j\right)=\delta_{0}+\delta_{1} \mathrm{AVAIL} i+\delta_{2} \mathrm{ACCESS} i+\delta_{3} \mathrm{Y} i+\delta_{4} \mathrm{FAMZ} i+\delta_{5} \mathrm{EDU} i+\delta_{6} \mathrm{OCC} i+\mu_{i}$ (6)

$\delta_{0}$ is the intercept in the model while $\delta_{1}-\delta_{6}$ is the parameters to be estimated in the model and $\mu_{i}$ is the error term in the model. All others as specified above.

\section{Result}

\section{A. Descriptive Statistics}


The data collected, processed and analyzed for this study were obtained randomly from 117 respondents from the study location which was short of the distributed questionnaire. From Table 1 under the mean column shows that majority of the respondents use traditional energy such as firewood, charcoal which is closely followed by the use kerosene. This is established by the value of the mean which is closer to 0 and 1 rather than 2 . The heavy use of traditional source of energy conforms to the norms in rural areas due its relative cheapness and availability. Accordingly, the mean value of energy availability, accessibility, income level and the income of household head shows positive effect of changes in the use of energy source. This thus means that when the availability and accessibility of one energy source increase relative to its alternate as well as changes in individual and household income, the choice of the use of energy will be affected. The number of family members as well has the possibility of causing changes in the use of energy. When the family is large, traditional energy sources will be preferred due to is relative cheapness and the cut of expenses. As such, the probability of an individual been educated or have a professional occupation or job will necessitate the choice of energy that will not affect or conflict with one's job or health.

Table 1: Descriptive Statistics

\begin{tabular}{|l|c|c|c|c|c|}
\hline \multicolumn{1}{|c|}{ Variable } & Observation & Mean & Std. Dev. & Min & Max \\
\hline Energy & 117 & 0.9487179 & 0.849403 & 0 & 2 \\
\hline Frequency & 117 & 2.512821 & 0.9433559 & 1 & 4 \\
\hline Availability & 117 & 0.7008547 & 0.459853 & 0 & 1 \\
\hline Accessibility & 117 & 0.6923077 & 0.4635236 & 0 & 1 \\
\hline Income & 117 & 0.7350427 & 0.4432086 & 0 & 1 \\
\hline Household Income & 117 & 0.5811966 & 0.4954851 & 0 & 1 \\
\hline Family Size & 117 & 0.7863248 & 0.4116631 & 0 & 1 \\
\hline Education & 117 & 0.5811966 & 0.4954851 & 0 & 1 \\
\hline Occupation & 117 & 0.6068376 & 0.4905533 & 0 & 1 \\
\hline
\end{tabular}

Sources: Author(s) Computation 2017

\section{B. Estimation Result and Discussion}

The analytical multinomial logistic model established in Eqn. (6) is analogous to the Multinomial logistic result in Table 2. The Pseudo $R^{2}$ is similar to the conventional $R^{2}$ although it does not directly mean same thing as the conventional OLS $\mathrm{R}^{2}$, although its 0.43 value is relatively fine as it attest to the goodness of the model. Accordingly, the log likelihood ratio accompanied by it probability value also shows the goodness of fit of the model. 
The availability of kerosene and modern energy sources (electricity and gas) relative to traditional energy sources (firewood and charcoal) positively influence the choice of kerosene and modern energy sources over traditional energy sources. Averagely, for a unit changes in the availability of kerosene and modern energy sources (electricity and gas) relative to that of traditional energy sources (firewood and charcoal) will likely lead to 4.41 and 3.14 changes in the multinomial log-odd of the preference of kerosene relative to traditional energy (firewood and charcoal) and modern energy (electricity and gas) relative to traditional energy (firewood and charcoal). This result corroborates with the assertions and findings of Desalu et al. (2012) and Danlami et al. (2015). When modern energy sources are available relatively to traditional energies, modern energies will be preferred. In contrast, when modern energies or kerosene are not available relative to traditional energies, traditional energies will be preferred. Thus the availability of energy is a major determinant of energy use in Lapai, as shown by its marginal effect; increase in the availability of kerosene and modern energies relative to traditional energies will cause the use of traditional energies to decline by $70 \%$. When an energy source is available, it will be used irrespective of socioeconomic factors.

Table 2: Multinomial Logistic Regression

Dependent Variable: $\operatorname{Pr}\left(\mathrm{ENEU}_{i}=j\right)$

\begin{tabular}{|c|c|c|c|c|c|}
\hline Variable & Coefficient & $P>|z|$ & Coefficient & $P>|z|$ & $d y / d x$ \\
\hline & \multicolumn{2}{|c|}{ Kerosene } & \multicolumn{2}{|c|}{ Electricity and Gas } & \\
\hline Constant & $\begin{array}{l}-8.978282 \\
(2.101281)\end{array}$ & $0.000 *$ & $\begin{array}{c}-5.57622 \\
(1.48494)\end{array}$ & $0.000 *$ & - \\
\hline AVAIL & $\begin{array}{c}4.405164 \\
(1.067115)\end{array}$ & $0.003 *$ & $\begin{array}{c}3.137736 \\
(0.8266343)\end{array}$ & $0.000 *$ & -0.7015496 \\
\hline ACCESS & $\begin{array}{c}2.412998 \\
(0.8223732)\end{array}$ & $0.028 * *$ & $\begin{array}{c}1.944536 \\
(0.7273869)\end{array}$ & $0.008 *$ & -0.4683724 \\
\hline $\mathrm{Y}$ & $\begin{array}{c}1.892975 \\
(0.8629121)\end{array}$ & $0.062 * * *$ & $\begin{array}{c}1.529679 \\
(0.7840213)\end{array}$ & $0.051 * *$ & -0.3782967 \\
\hline FAMZ & $\begin{array}{c}2.37957 \\
(1.275309)\end{array}$ & $0.001 *$ & $\begin{array}{c}1.289265 \\
(0.8387682)\end{array}$ & $0.124 * * *$ & -0.3670119 \\
\hline EDU & $\begin{array}{c}2.977653 \\
(0.8920126)\end{array}$ & $0.028 * *$ & $\begin{array}{c}2.360137 \\
(0.8092965)\end{array}$ & $0.004 *$ & -0.5364115 \\
\hline OCC & $\begin{array}{c}-1.935482 \\
(0.8829392)\end{array}$ & $0.000 *$ & $\begin{array}{c}-1.862047 \\
(0.8256547)\end{array}$ & $0.024 * *$ & 0.3690286 \\
\hline
\end{tabular}

Similarly accessibility or affordability of energy sources positively influence energy used. Ceteris paribus a unit change in the accessibility or affordability of kerosene relative to 
traditional energy and modern energies relative to traditional energies will likely cause the multinomial log-odds of kerosene relative to traditional energies and modern energies relative to traditional energies to change by 2.41 and 1.95 . The use of energies that are affordable is a common norm in rural areas. This relationship conforms to the findings of Desalu et al. (2012) and Bamiro and Ogunjobi (2015). When kerosene or modern energies (electricity and gas) are easily accessible and affordable the use of traditional energies (firewood and charcoal) will decline. The heavy use of traditional energies thus relate to the nonaccessibility and expensiveness of modern energies and kerosene compared to the cheapness and freeness to some extent as well as their easy access. As such, the use of traditional energies will reduce by $47 \%$ as a result of increase in the access or affordability of kerosene and modern energies relative to traditional energies.

Income level and family size are also key determinants of the use of modern energies relative to traditional energies in Lapai. Changes in income level and family size by a unit will likely cause the multinomial log-odds of the use of kerosene relative to traditional energy sources to increase by 1.89 and 2.38 while the multinomial log-odds of modern energies use relative to the use of traditional energy use will likely increase by 1.53 and 1.29 respectively as a result of changes in income level and family size. The positive influence of changes in income level and family size to the use of kerosene and modern energies (electricity and gas) corroborates with the findings of Desalu et al. (2012), Danlami et al. (2015), Emagbetere et al. (2016) and Ogwumike et al. (2014) although it counters the findings of Ogwumike et al. (2014) on the negative relationship between changes in family size and the use kerosene and modern energies. The marginal effect thus shows that changes in the use of kerosene and modern energies relative to the use of traditional energies as a result of changes in income and family size will lead to $38 \%$ and $37 \%$ decrease in the use traditional energies respectively.

Accordingly, the level of education positively influences the use of kerosene and modern energies relative to traditional energies (firewood and charcoal) while the nature of occupation negatively influences the use of kerosene and modern energies (electricity and gas). On average, a unit change in education level will likely result to 2.98 and 2.36 changes in the multinomial log-odds of the use kerosene and modern energies relative to the use of traditional energies respectively. While the multinomial log-odds of the use of kerosene and modern energies relative to the use of traditional energies (firewood and charcoal) will decline by 1.94 and 1.86 respective. The positive relationship between educational level and the choice of energies upheld the findings of Desalu et al. (2012), Ogwumike et al. (2014) 
and Emagbetere et al. (2016), while disproving the findings of Danlami et al. (2015) and Emagbetere et al. (2016) that changes in occupation will positively influence the choice of the use of energies. The marginal effect of educational level shows that changes in educational level will lead to $54 \%$ decrease in the use of traditional energy sources relative to the use of kerosene and modern energies, while the use of traditional energies relative to kerosene and modern energies will be increase by $37 \%$ as a result to changes in occupation. Thus educational level and occupation are major determinants of energy use in Lapai.

Conclusively, from above it can be noted that while availability of energy sources, affordability or accessibility of energy sources, income level, family size, educational level influences the choice of the use of kerosene and modern energy sources positively, the nature of one's occupation negatively influence the use of kerosene and modern energy sources in favor of the use of traditional energy sources (firewood, charcoal) in Lapai.

\section{Conclusion}

The paper investigates the determinants of energy use in Lapai Local government are of Niger state, Nigeria using a cross-sectional data randomly collected from 117 respondents in the Lapai. Employing the descriptive statistics and Multinomial Logistics regression model to capture the characteristics of the respondents and the determining factors of energy use in Lapai respective, the empirical result obtained revealed that the availability and affordability of kerosene and modern energy sources (electricity) relative to traditional energy sources (firewood and charcoal), income level, family size and educational status positively determine the use of kerosene and modern energy sources relative to traditional energy sources while occupational status of individuals negatively determine the use of kerosene and modern energy sources in favor of the use of traditional energy sources. Thus overall from the study, availability and affordability or accessibility of energy sources, income level, family size, educational status and the nature of occupation are the determinants of energy use in Lapai.

\section{A. Recommendations}

The following recommendations are made based on the findings from the study; Since availability and affordability are increasing function of the use of modern clean energy sources, the availability as well as accessibility of modern energies should be further enhanced in Lapai. When electricity is available and accessible for instance, the use of electricity relative to the use of firewood and charcoal will increase, as such the environment will be free from air pollution it has been subjected to due to the use of traditional energy sources. 
Accordingly, the minimum wage which will increase the income level of individuals should be clamored for. When income level increases, the use of cleaner modern energy sources will increase.

The Government through ministry of power and environment should come up with suitable policies that will shift the attention of using biomass energy source to modern energy source.

Government and environmental agencies should introduce safe and sufficient energy source in other to reduce burden on the use of biomass in the country so as to reduce the level of pollution and erosion.

There should be proper awareness to the people on the environmental effects of the use of biomass as the majority of the people are not aware of its negative effect to the environment.

Laws that will reduce deforestation should be formulated by relevant agencies. This is because the biomass uses as energy source are firewood and charcoal which is all product of trees.

Finally, as a major determinant of energy use in Lapai, access to education should be enhanced by way of scholarship. 


\section{References}

Adepoju, A.O., Oyekale, A.S. and Aromolaran, O. (2012), "Factors Influencing Domestic Energy Choice of Rural Households in Ogun State, Nigeria". Journal of Agriculture and Social Sciences, Vol. 8, No. 4, pp. 129-134.

Adeyemi P. A., and A. Adereleye A., (2016) Determinants of Household Choice of Cooking Energy in Ondo State, Nigeria. Journal of Economics and Sustainable Development vol. 7, No 9. Pp 131-142

Bamiro, O.M. and Ogunjobi, J.O. (2015). "Determinants of Household Energy Consumption in Nigeria: Evidence from Ogun State". Research Journal of Social Science and Economics, Vol. 4, No. 12, pp. 35-41.

Baland J., Bardhan, P., Das, S., Mookhejee, D., Sakar, R. (2007), Managing the Environmental Consequences of Growth: Forest Degradation in the Indian MidHimalayas. Indian Policy Forum, 3, 215-227

Baldwin, S. (1986), Biomass Stove: Engineering Design, Development and Dissemination Arlington. VITA

Barnes, D. F., Floor, W. (1999), Biomass Energy and the Poor in Developing World. Journal of International Affair, 53(1), 237-259

Bekele, G., Negatu, W. and Eshete, G. (2016), "Determinants of Household Energy Demand in Ethiopia: The Case Study of Addis Ababa City". Applied Economics and Finance, Vol. 3, No. 1, pp. 1-14.

Dzioubinski, O., Chipman, R. (1999), Trends in Consumption and Production: Household Energy Consumption: United Nation Department of Economics and Social Affairs Discussion Paper 6

Danlami, A.H., Islam, R. and Applanaidu, S.D. (2015). "An Analysis of the Determinants of Households' Energy Choice: A Search for Conceptual Framework". International Journal of Energy Economics and Policy, Vol. 5, No. 1, pp.197-205

Desalu, O.O., Ojo, O.O., Ariyibi, E.K., Kolawole, T.F. and Ogunleye, A.I. (2012). “A community survey of the pattern and determinants of household sources of energy for cooking in rural and urban south western, Nigeria". Pan African Medical Journal, pp. $1-12$.

Emagbetere, E., Odia, J. and Oreko, B.U. (2016). “Assessment of Household Energy Utilized For Cooking In Ikeja, Lagos State, Nigeria". Nigerian Journal of Technology (NIJOTECH), Vol. 35, No. 4, pp. $796-804$.

Hosier, R., Dowd, J. (1987), Household Fuel Choice in Zimbabwe: An Empirical Test of energy Ladder Hypothesis. Resources and Energy, 9(4), 347-361

Hosier, R., Kipondya, W. (1993), Urban Household Energy Use in Tanzania: Price, Substitutes, and Poverty. Energy Policy, 21(5), 453-473

Jackson, T. (2005), Motivating Sustainable Consumption. A Review of Evidence on Consumer Behaviour and Behavioural Change. A Report Submitted to the Sustainable Development Research Network.

Mekonnen, A., Kohlin, G. (2008), Determinant of Household Fuel Choice in Major Cities in Ethiopia. University of Gothenburg, School of Business, Economics and Law, Working Papers in Economics No. 399

Ouedraogo, B. (2006), Household Energy Preference for Cooking in Urban Ouagadougou, Burkina Faso. Energy Policy, 34(18), 3787-3795.

Ogwumike, F. O., Ozughalu, U.M. and Abiona, G.A. (2014). "Household Energy Use and Determinants: Evidence from Nigeria". International Journal of Energy Economics and Policy, Vol. 4, No. 2, pp.248-262. 
Onoja, A.O. and Idoko, O. (2012), "Econometric Analysis of Factors Influencing Fuel Wood Demand in Rural and Peri-Urban Farm Households of Kogi State". Consilience: The Journal of Sustainable Development, Vol. 8, Issue 1, Pp. 115-127.

Sakanko, A. M. and Obilikwu, J. (2018). Empirical analyzed the determinants of demand for charcoal in Niger State. Fudma economic and development review (FDER), Vol. 2, No. 1 , pp 60 - 70

Rojmohan, K., Weerahewa, J. (2007). Household Energy Consumption Pattern in Sir Lanka. Journal of Agricultural Economics, 9(1), 55-77

World Bank. (2003), Household Energy Use in Developing Countries: A Multicountry Study. World Bank ESMAP. Technical Paper No 42. 